\title{
STUDY OF DIRECT COMPRESSION METHOD FOR THE PREPARATION OF QUINAPRIL HYDROCHLORIDE TABLETS
}

\author{
SHWETHA MARGRET JL ${ }^{1}$, MADHAVI BLR ${ }^{2 *}$ \\ ${ }^{1}$ Department of Pharmaceutics, RBVRR Women's College of Pharmacy, Barkatpura, Hyderabad, Telangana, India. ${ }^{2}$ Department of \\ Pharmaceutics, Acharya and BM Reddy College of Pharmacy, Bengaluru, Karnataka, India. Email: madhaviblr@gmail.com
}

Received: 09 May 2019, Revised and Accepted: 30 November 2019

\begin{abstract}
Objective: Direct compression method is preferable for tablet manufacture. The direct compression method is followed for many formulations but the relevant study is not reported. The present work aims to study the suitability of the direct compression process to prepare tablets of quinapril hydrochloride $(\mathrm{QHCl})$, a low dose drug with a starting dose of $5 \mathrm{mg}$, indicated in the treatment of hypertension, congestive heart failure, and other conditions.

Methods: $\mathrm{QHCl}$ is reported to be unstable in the presence of moisture, heat, and some excipients. The direct compression method was tried instead of a wet granulation technique to prepare the tablets. Initially, drug-excipient compatibility study was carried out. For selected excipients and QHCl preformulation tests were conducted. The stabilizer was employed. Three formulations were tried. The blends were prepared by tumbling and trituration methods. Blend uniformity and precompression parameters were determined. Tablets were directly compressed and evaluated.

Results: Drug-excipient compatibility was studied at $60^{\circ} \mathrm{C}$ and $40^{\circ} \mathrm{C}$ with an Relative humidity (RH) of $75 \%$ for 4 weeks. It showed discoloration of the pure drug and most of the drug excipient mixtures. Three formulations Q1, Q2, and Q3 were prepared using magnesium oxide (light), magnesium carbonate (light), and Aerosil as stabilizers. Blending was done by trituration and tumbling method for $10 \mathrm{~min}$ and $15 \mathrm{~min}$ duration for the given batch size. Blend uniformity was determined. Tumbling method for 15 min showed good blending as evident from the percentage coefficient of variation values. The blends had a good flow. Tablet evaluation showed hardness in the range of $2.5-3 \mathrm{~kg} / \mathrm{cm}^{2}$ and disintegration time of $1-2$ min. Q1 and Q2 passed the friability test. The content uniformity criterion was achieved with an acceptance value $<20$. In vitro dissolution, Q1 and Q2 were $100 \%$ and $98.8 \%$, respectively, in 30 min and followed first-order kinetics. The stability study of Q1 indicated a single peak in the chromatogram corresponding to the drug. Q2 showed spotted discoloration.
\end{abstract}

Conclusion: The direct compression technique could be employed for the preparation of QHCl tablets. Q1 showed better stability and release characteristics. Q2 and Q3 are considered for further study.

Keywords: Quinapril hydrochloride, Tablets, Direct compression, Blend uniformity, Content uniformity, Stabilizer.

(C) 2020 The Authors. Published by Innovare Academic Sciences Pvt Ltd. This is an open access article under the CC BY license (http://creativecommons. org/licenses/by/4. 0/) DOI: http://dx.doi.org/10.22159/ajpcr.2020.v13i.134005

*This work has been presented in part at the $66^{\text {th }}$ Indian Pharmaceutical Congress, January 2015, Hyderabad, Andhra Pradesh, India

\section{INTRODUCTION}

Tablet is the most popular dosage form existing today because of its convenience of self-administration, compactness, and ease of manufacturing. Tablets may be manufactured by compression granulation and direct compression methods. There has been a growing impetus to develop direct compression formulations. Fluidity and compressibility are prerequisites for direct compression technology [1]. Quinapril hydrochloride (QHCl) is used in the treatment of hypertension or congestive heart failure [2]. The main drawback of $\mathrm{QHCl}$ is its instability [3-6]. It is highly unstable in the presence of moisture, temperature, and excipients. It gets degraded to diketopiperazine in acidic $\mathrm{pH}$ and diacid in alkaline $\mathrm{pH}$; it undergoes oxidative degradation leading to discoloration. $\mathrm{QHCl}$ is a low dose drug (5 mg-80 mg). The literature review indicates that tablets of many low dose drugs such as felodipine [7], diazepam [8], and nitroglycerin [9] have been prepared by direct compression. Magnesium oxide [10], magnesium carbonate [11], and ascorbic acid [12] have been reported as stabilizers for $\mathrm{QHCl}$ as $\mathrm{pH}$ modifiers. Gastroretentive has been prepared by direct compression for $\mathrm{QHCl}$ and has been employed in the preparation of gastroretentive floating tablets [13]. In the present work, the suitability of preparation of $\mathrm{QHCl}$ tablets employing stabilizers by direct compression method is studied.

\section{METHODS}

QHCl was obtained as a gift sample from Aurobindo Pharma Limited. Crospovidone was procured from NR Chemicals. Lactose monohydrate, hydroxypropylmethylcellulose, magnesium carbonate (Light), magnesium oxide (Light), Aerosil, talc, and other analytical grade reagents were supplied by SD Fine Chemicals Ltd.

Estimation of QHCl by ultraviolet-visible (UV-Vis) spectroscopy $\mathrm{UV}$-vis spectroscopic method is developed for the estimation of $\mathrm{QHCl}$ in distilled water at $220 \mathrm{~nm}$ with placebo as blank $(\mathrm{n}=6)[13,14]$.

\section{Stability of aqueous solution of $\mathrm{QHCl}$}

Known concentration of $\mathrm{QHCl}$ solution in distilled water was prepared. The absorbance was measured at time points of $0,30,60$, 90 , and $120 \min (n=3)$. The stability of $\mathrm{QHCl}$ in aqueous solution was determined for the purpose of the evaluation of dissolution study samples.

Estimation by Fourier-transform infrared spectroscopy (FTIR) Infrared spectroscopy (IR) spectrum of the sample was generated employing potassium bromide $(\mathrm{KBr})$ disk method for $\mathrm{QHCl}$ and drugexcipient mixtures, where necessary methanolic solution of the sample was added to $\mathrm{KBr}$ and triturated. The mixture was allowed to dry and then compacted for analysis. Adequate care was taken to avoid moisture contamination. 
Estimation by High Performance Liquid Chromatography (HPLC) HPLC method was developed for the detection of any instability in the drug during formulation and storage [14]. It is employed for a minimal qualitative purpose in this work. Known concentration of $\mathrm{QHCl}$ solution in distilled water (HPLC Grade) was prepared and filtered through $0.45 \mu \mathrm{m}$ filter. Analytical column (ODS Inertsil, $250 \mathrm{~mm} \times 4.6 \mathrm{~mm}, 5 \mu$ particle size) was used as a stationary phase. A UV-vis detector was set to $214 \mathrm{~nm}$. The mobile phase was composed of acetonitrile phosphate buffer $\mathrm{pH} 2(50: 50 \mathrm{v} / \mathrm{v}) .10 \mu \mathrm{l}$ of sample volume was injected into the column with isocratic elution at a flow rate of $1 \mathrm{ml} / \mathrm{min}$ for a run time of $6 \mathrm{~min}$. Tablet samples/degraded pure drug samples were first extracted into methanol and further dilutions were made with distilled water (HPLC grade) and analyzed as mentioned above.

\section{Preformulation studies}

Determination of melting point, moisture content analysis by moisture balance, particle size and shape analysis by optical microscopy, determination of flow property by angle of repose, and bulk and tapped densities were carried out for $\mathrm{QHCl}$ and selected excipients.

\section{Drug excipient compatibility study}

Drug excipient compatibility study [15] was performed by taking physical mixtures of drug and excipient (D+E) the ratio of 1:1 $(n=3)$ in glass vials. Pure drug and pure excipient were employed as control at all conditions of the study. All the samples were stored for a period of 4 weeks, respectively, at $40^{\circ} \mathrm{C}$ and $75 \% \mathrm{RH}, 25^{\circ} \mathrm{C}$ and $60 \% \mathrm{RH}$ employing a humidity chamber (Newtronic $204 \mathrm{ETS}$ ) and at $60^{\circ} \mathrm{C}$ in an oven (Biotech). Samples were taken at regular intervals of 1, 2, 3, and 4 weeks for evaluation by physical observation and FTIR. Various fillers, binders [16], disintegrants, stabilizers, and lubricants were studied for compatibility with drug for direct compression method.

\section{Formulation of QHCl tablets}

After evaluating D+E compatibility and excipients properties, $\mathrm{QHCl}$ tablets were formulated (Table 1).

\section{Preparation of tablets}

After collecting the raw materials, blending was carried out by employing trituration and tumbling methods independently. Trituration was carried out in mortar and pestle. Tumbling was carried out using polybags. Powders were blended for $10 \mathrm{~min}$ and $15 \mathrm{~min}$, respectively, in each trial by trituration/tumbling. Talc was then added and blended for another $3 \mathrm{~min}$

\section{Blend uniformity determination}

The powder blend was taken on a flat surface and it was leveled to a known thickness. Sample of weight equivalent to three tablets was collected from five locations - the four corners and center from medial height and estimated for drug content. Standard deviation and percentage coefficient of variation $(\% \mathrm{CV})$ are calculated.

\section{Pre-compression parameters of blend}

The blend was evaluated for precompression parameters such as angle of repose, bulk density, and tapped density.

Table 1: Formulation of quinapril hydrochloride tablets

\begin{tabular}{llll}
\hline Ingredients (mg/tablet) & Q1 & Q2 & Q3 \\
\hline QHCl ( 10 mg of quinapril) & 10.83 & 10.83 & 10.83 \\
Lactose monohydrate & 102 & 102 & 102 \\
Crospovidone & 2.8 & 2.8 & 2.8 \\
HPMC E50 LV & 5.8 & 5.8 & 5.8 \\
Magnesium oxide (light) & 2.43 & - & - \\
Magnesium carbonate (light) & - & 2.43 & - \\
Aerosil-200 & - & - & 2.43 \\
Talc & 1.23 & 1.23 & 1.23 \\
Weight of the tablet (mg) & 125 & 125 & 125 \\
\hline
\end{tabular}

Compression of $\mathrm{QHCl}$ tablets

Tablets were prepared by direct compression using $6 \mathrm{~mm}$ circular, flat-faced punches on the rotary tablet compression machine (Model Minipress-1, Gujarat).

\section{Evaluation of tablets}

The tablets were evaluated for hardness, thickness, friability, disintegration time, weight variation, and for content uniformity [17].

\section{In vitro dissolution study}

The in vitro dissolution of QHCl tablets was studied using USP Dissolution Apparatus Type II (Paddle Type) Electrolab model no. Fourteen liter in $900 \mathrm{ml}$ of distilled water (media) maintained at $37^{\circ} \mathrm{C} \pm 0.5^{\circ} \mathrm{C}$ and $100 \mathrm{rpm}$. The collected samples were filtered and analyzed by UV-vis spectrophotometer after suitable dilutions. A correction factor for the drug lost during sampling was incorporated while calculating the cumulative percentage dissolved.

\section{Stability study}

Selected tablets were subjected to preliminary stability studies at $40^{\circ} \mathrm{C} \pm 2^{\circ} \mathrm{C}, 75 \pm 5 \% \mathrm{RH}$ for period of 1 month. Tablets were stored in glass vials in a humidity chamber (Newtronic 204 ETS). Three tablets were analyzed for appearance and drug content. Selected samples were analyzed by HPLC.

\section{RESULTS AND DISCUSSION}

\section{UV-Vis Spectrophotometric method}

Calibration curve was constructed (Fig. 1). The method was validated for linearity $\left(r^{2}=0.99\right)$, accuracy and precision (\% CV $\left.<5 \%\right)$. The method obeyed Beer's law in the concentration range of $2-15 \mu \mathrm{g} / \mathrm{ml}$.

\section{Stability of aqueous solution of $\mathrm{QHCl}$}

No significant change in absorbance was observed when measured at $220 \mathrm{~nm}$ (Table 2). The aqueous solution of the drug was thus determined to be stable during $2 \mathrm{~h}$ period and for measurement of dissolution study samples.

\section{Estimation by FTIR}

FTIR spectrum could be generated by $\mathrm{KBr}$ disk method. All the peaks corresponding to the pure drug were retained in the FTIR spectrum (Fig. 2)

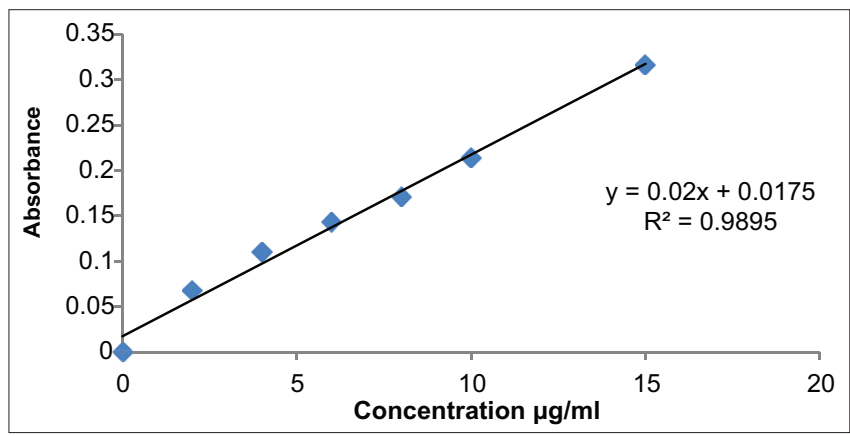

Fig. 1: Standard curve of quinapril hydrochloride

Table 2: Stability of aqueous solution of quinapril hydrochloride

\begin{tabular}{llll}
\hline \multirow{2}{*}{ Time (min) } & \multicolumn{3}{l}{ Absorbance at 220 nm } \\
\cline { 2 - 4 } & Sample 1 & Sample 2 & Sample 3 \\
\hline 0 & 0.175 & 0.175 & 0.173 \\
15 & 0.177 & 0.176 & 0.177 \\
30 & 0.179 & 0.177 & 0.177 \\
60 & 0.172 & 0.175 & 0.175 \\
120 & 0.177 & 0.176 & 0.175 \\
180 & 0.172 & 0.175 & 0.177 \\
\hline
\end{tabular}


Estimation by HPLC

Chromatogram could be developed (Fig. 3) and showed a single peak with a retention time of $3.8 \mathrm{~min}(\mathrm{n}=4)$. The chromatogram of degraded $\mathrm{QHCl}$ obtained when stored at $60^{\circ} \mathrm{C}$ and at $40^{\circ} \mathrm{C} / 75 \% \mathrm{RH}$ (Figs. 4 and 5) gave retention time of $4.2 \mathrm{~min}$ and $3.3 \mathrm{~min}$, respectively.

\section{Excipient compatibility study}

QHCl control sample showed color change during physical observation in 2 weeks when stored at $60^{\circ} \mathrm{C}$ and within a week when stored at $40^{\circ} \mathrm{C}$ and $75 \% \mathrm{RH}$. It remained unchanged on physical observation at $25^{\circ} \mathrm{C}$ and $60 \% \mathrm{RH}$ when studied up to 4 weeks. Hence, ambient working condition for the drug is moderate room temperature $\left(25^{\circ} \mathrm{C}\right)$ and low humidity which has been maintained during the study period. Discoloration of D+E mixtures to dark pink/dark brown occurred in most of the cases (Table 3 and Fig. 6) except with lactose, crospovidone, Hydroxypropyl methylcellulose (HPMC), magnesium oxide (light), magnesium carbonate, Aerosil, and talc. At $25^{\circ} \mathrm{C}$ and $60 \% \mathrm{RH}$ in a 4 weeks study no perceivable change was observed with most of the excipients. Hence, for the unchanged D+E mixtures, FTIR spectra were analyzed (Fig. 7). From all the spectra, it could be seen that characteristic

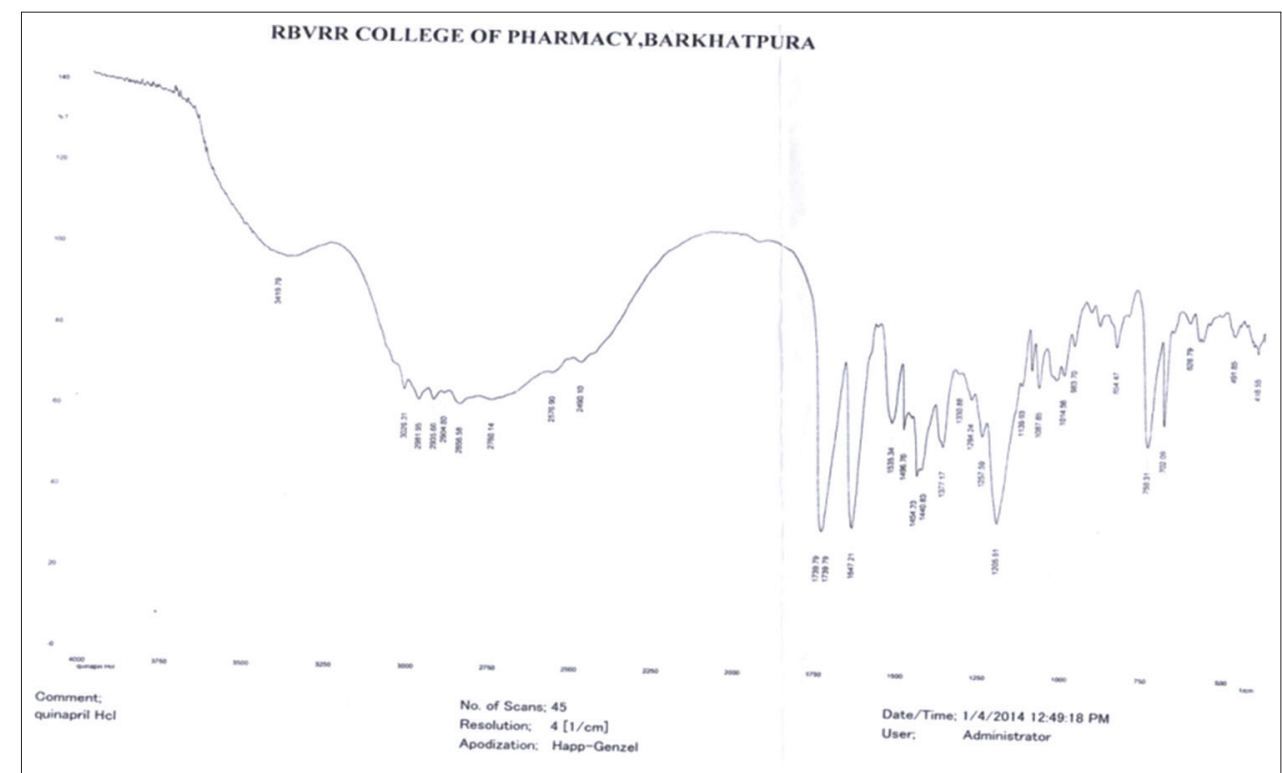

Fig. 2: FTIR spectrum of quinapril hydrochloride

Table 3: Drug excipient compatibility studies

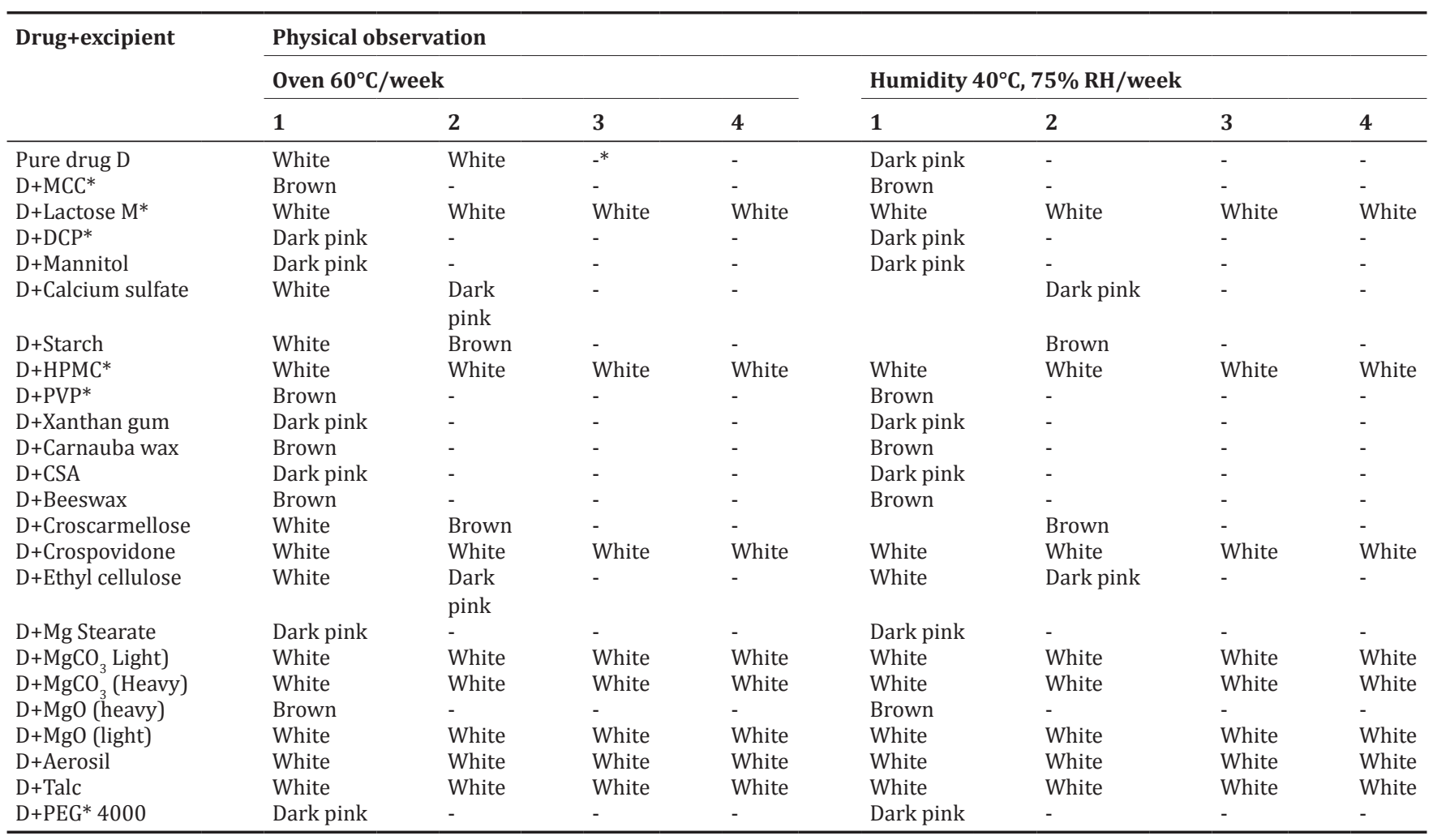

*Lactose M: Lactose Monohydrate, DCP: Dicalcium phosphate, HPMC: Hydroxypropylmethylcellulose, PVP: Polyvinylpyrrolidone, CSA: Cetostearyl alcohol,

PEG: Poly Ethylene Glycol, MCC: Microcrystalline Cellulose, “-” study not continued, RH: Relative humidity 
peaks of $\mathrm{QHCl}$ were retained. Hence, these excipients were employed in the preparation of QHCl tablets. Literature shows studies carried out for the compatibility of $\mathrm{QHCl}$ with HPMC and lactose $[3,4]$.

\section{Preformulation study of drug and excipients}

The pure drug and excipients were evaluated for various physical properties (Table 4). The melting point of the drug was found to be $119^{\circ} \mathrm{C}$ in accordance with reported data. The moisture content of pure drug was found to be very low at $0.1 \%$. Angular/tabular particle shape (Fig. 8) angle of repose (45.6 $)$, Carr's Index and Hausner's ratio 44.14 and 1.44 , respectively, indicate that $\mathrm{QHCl}$ had very poor flow property. Particle size was analyzed by optical microscope. Mean size was found to be $15.75 \mu \mathrm{m}$. The angle of repose and Carr's index values of each excipient indicate good to passable flow for most of them except $\mathrm{MgCO}_{3}$ and lactose. It is observed that bulk and tapped densities of lactose and HPMC were higher than $\mathrm{QHCl}$ density of crospovidone, MgO (light) and $\mathrm{MgCO}_{3}$ (light) were lower than $\mathrm{QHCl}$ and were used in low percentage in the formulation. The moisture content of all the excipients which were used in the formulation was very low. The particle size lactose and HPMC used in higher percentage in formulation were close to that of QHCl. All other excipients were in the lower size range. The influence of particle shape and size is clearly reflected in the flow characteristics. Lactose with angular shape showed the poorest flow. HPMC had fibers and spherical particles and showed passable flow. Although particle size is small and shape is spherical, it can be seen that $\mathrm{MgCO}_{3}$ had poor flow and this may be due to static electricity which leads to adhesiveness of particles [18]. Large variation in micromeritic properties leads to segregation during the direct compression process. However, above study indicates suitability of the drug and excipient combination for the same.

\section{Pre-compression parameters of blend}

The formulation of tablets is based on Table 1 . The precompression parameters of the blend (Table 5) showed that the angle of repose

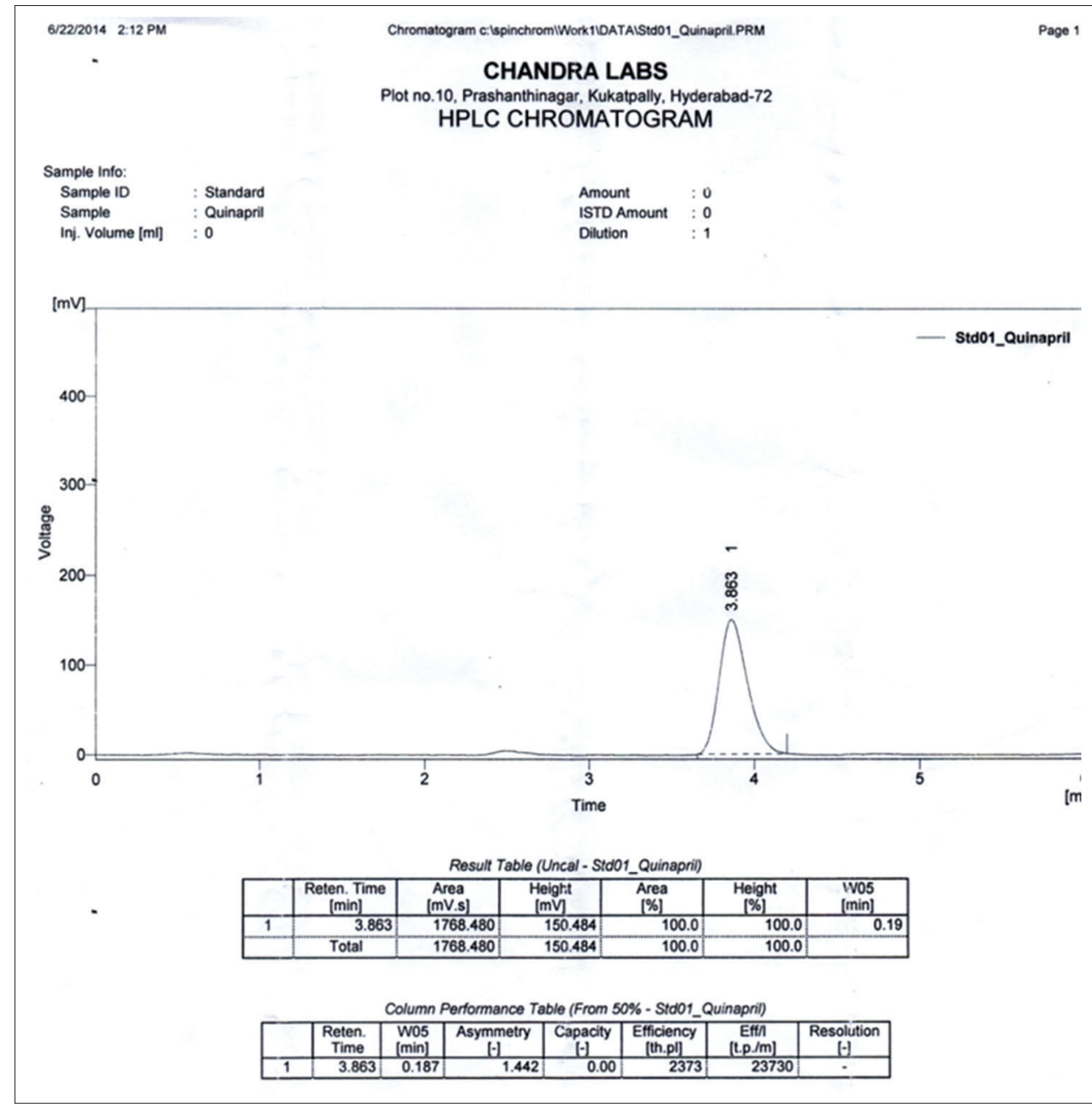

Fig. 3: Chromatogram of quinapril hydrochloride

Table 4: Study of excipient properties

\begin{tabular}{|c|c|c|c|c|c|c|c|}
\hline Parameter & QHCl & Lactose M & HPMC & Crospovidone & Mg0 & $\mathrm{MgCO}_{3}$ & Aerosil \\
\hline Angle of repose $(\theta)$ & 45.6 & 56.7 & 37.23 & 16.17 & 39.2 & 49.62 & 15.7 \\
\hline Bulk density $(\mathrm{g} / \mathrm{ml})$ & 0.36 & 0.47 & 0.41 & 0.25 & 0.17 & 0.27 & 0.24 \\
\hline Tapped density $(\mathrm{g} / \mathrm{ml})$ & 0.52 & 0.62 & 0.50 & 0.35 & 0.22 & 0.40 & 0.32 \\
\hline Compressibility index (\%) & 44.14 & 31.9 & 21.95 & 40 & 29.41 & 48.14 & 33.33 \\
\hline Moisture (\%) & 0.1 & 3.2 & 0.8 & 0.1 & 0.8 & 0.8 & 0.2 \\
\hline Particle size $(\mu \mathrm{m})$ & 15.75 & 17.25 & 11 & 4.6 & 3.02 & 3.76 & 1 \\
\hline Particle shape & Angular/tabular & Angular/tabular & Granular/fibrous & Spherical agglomerates & Spherical & Spherical & Spherical \\
\hline
\end{tabular}

QHCl: Quinapril hydrochloride, HPMC: Hydroxypropylmethylcellulose 


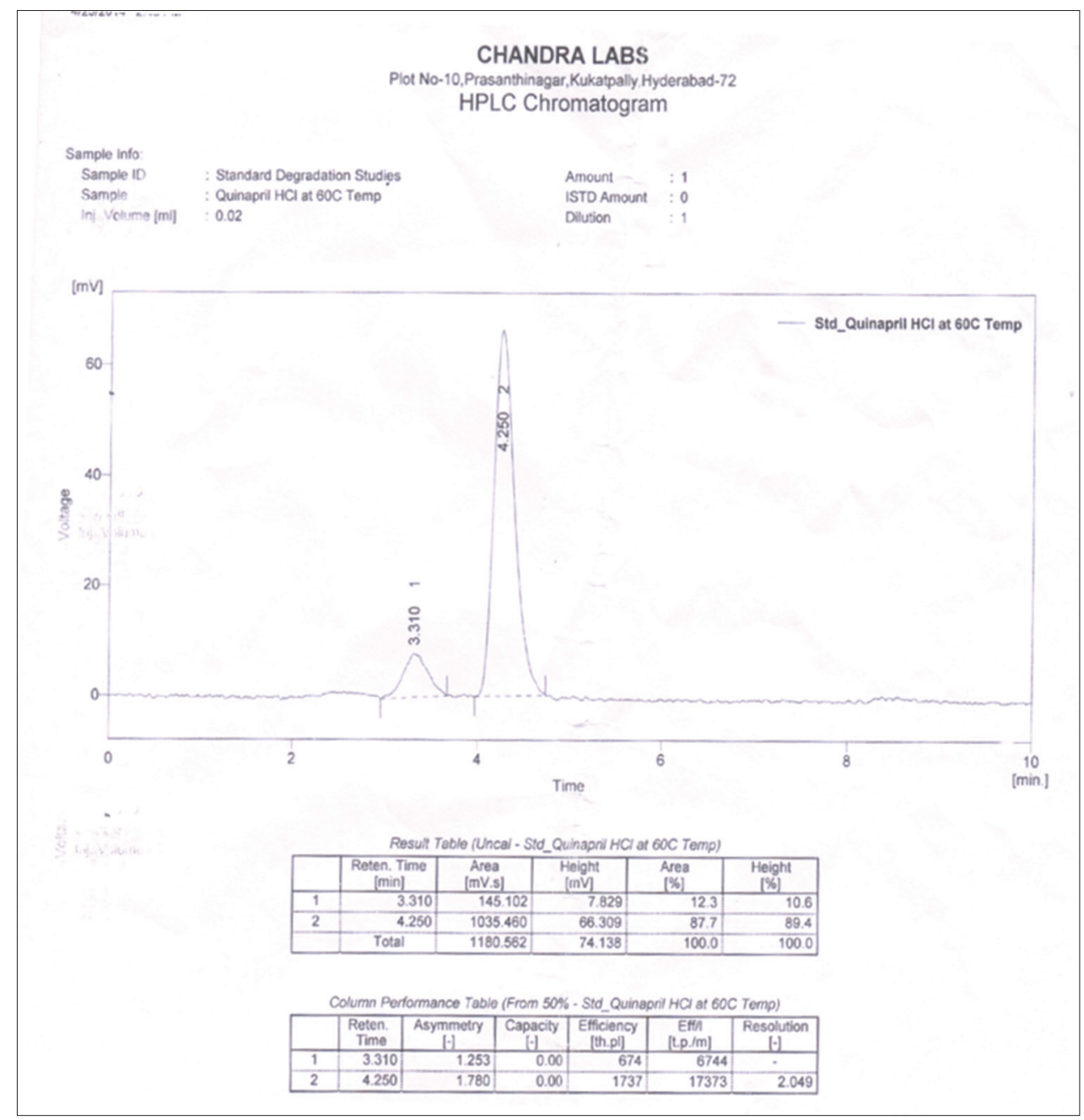

Fig. 4: Chromatogram of quinapril hydrochloride stored at $60^{\circ} \mathrm{C}$

Table 5: Precompression parameters of powder blend of quinapril hydrochloride formulations

\begin{tabular}{llll}
\hline Parameter & Q1 & Q2 & Q3 \\
\hline Angle of repose $(\theta)$ & 25 & 25 & 26 \\
Bulk density $(\mathrm{g} / \mathrm{ml})$ & 0.45 & 0.46 & 0.28 \\
Tapped density $(\mathrm{g} / \mathrm{ml})$ & 0.40 & 0.40 & 0.20 \\
Hausner's ratio & 0.88 & 0.86 & 1.4 \\
Compressibility index $(\%)$ & 11.11 & 13.04 & 28.57 \\
Moisture content \% & 0.1 & 0.2 & 0.1 \\
\hline
\end{tabular}

is $25-26^{\circ}$ indicating that blend has improved flow compared to the individual excipients. The values for Carr's Index and Hausner's ratio also are in agreement with the angle of repose values for Q1, Q2, and Q3.

\section{Blend uniformity}

Tumbling and trituration method was compared for blending. From Table 6, \% CV values for $\mathrm{QHCl}$ content in the samples indicated variation. For Q1 formulation, the \% $\mathrm{CV}$ values were higher for the trituration method compared to tumbling method. This may be because during trituration, the entire powder blend will not be subject to displacement from the previous position and there may be dead zones. With tumbling method, geometric dilution was followed to blend drug and diluents. $\mathrm{QHCl}$ and lactose have moderate similarity in particle size shape and density $(15.75 \mu \mathrm{m}$ and $17.25 \mu \mathrm{m}$; angular and tabular; $0.36 \mathrm{~g} / \mathrm{ml}$ and $0.47 \mathrm{~g} / \mathrm{ml}$ ), respectively (Table 4 ). The other excipients which were added subsequently get interspersed between
Table 6a: Blend uniformity study for Q1

\begin{tabular}{llllllll}
\hline Amount of QHCl in mg after specific blending time \\
\hline Method & $\begin{array}{l}\text { Sample* } \\
\text { position }\end{array}$ & \multicolumn{1}{l}{$\mathbf{1 0}$ min } \\
& \multicolumn{7}{c}{$\mathbf{1 5}$ min } \\
\hline Tumbling & BL & 12.78 & 13.22 & 13.27 & 12.78 & 12.08 & 13.22 \\
& BR & 13.22 & 13.43 & 11.85 & 12.69 & 11.85 & 13.40 \\
& FL & 12.49 & 13.20 & 11.67 & 12.45 & 11.55 & 12.83 \\
& FR & 12.70 & 13.10 & 13.59 & 13.13 & 12.78 & 12.70 \\
& C & 12.97 & 13.06 & 13.45 & 12.70 & 12.35 & 13.20 \\
& $\%$ CV & 2.23 & 1.08 & 4.26 & 1.92 & 3.87 & 2.23 \\
& Mean & 2.5 & & & 2.67 & & \\
\% CV & & & & & & \\
Trituration & BL & 11.49 & 9.53 & 10.07 & 10.48 & 8.45 & 11.05 \\
& BR & 9.53 & 7.95 & 9.71 & 9.21 & 8.96 & 10.71 \\
& FL & 9.36 & 9.18 & 9.53 & 8.43 & 9.19 & 11.51 \\
& FR & 9.55 & 9.0 & 8.73 & 8.95 & 9.41 & 10.78 \\
C & 9.18 & 8.11 & 9.69 & 8.73 & 7.95 & 11.30 \\
& $\%$ CV & 9.00 & 7.88 & 5.19 & 8.63 & 6.71 & 3.06 \\
Mean & 7.35 & & & 6.13 & & \\
\% CV & & & & & & \\
\hline
\end{tabular}

*BL: Back left, BR: Back right, FL: Front left, FR: Front right, C: Centre, $\% \mathrm{CV}$ : Percentage coefficient of variation, $\mathrm{QHCl}$ : Quinapril hydrochloride

the blend due to the smaller particle size and a convenient spherical shape. The smaller particles may also adsorb on to the larger ones. Differences in particle size are the most common cause of segregation in pharmaceutical powders. However, when component of a powder 


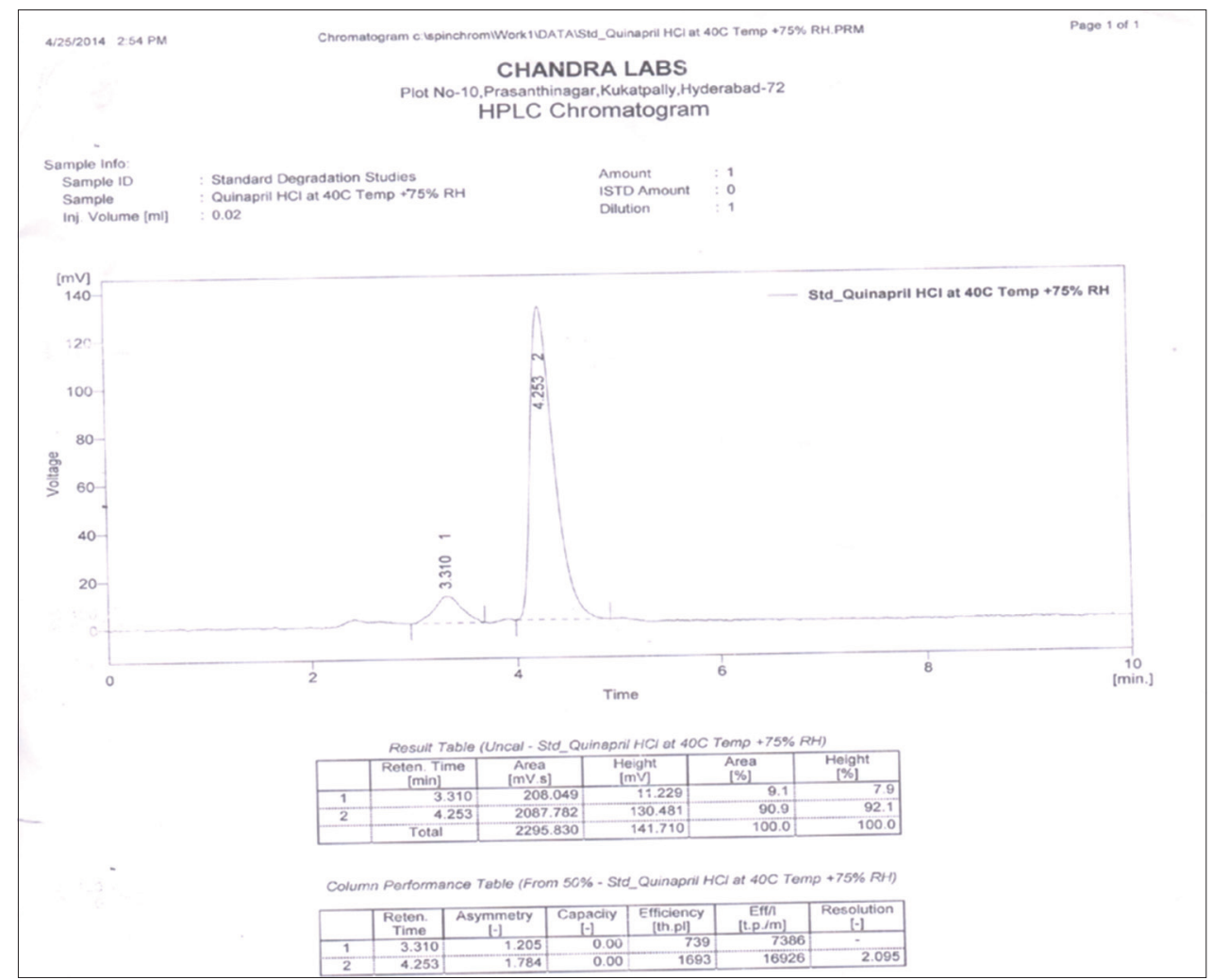

Fig. 5: Chromatogram of quinapril hydrochloride stored at $45^{\circ} \mathrm{C}$ and $75 \% \mathrm{RH}$
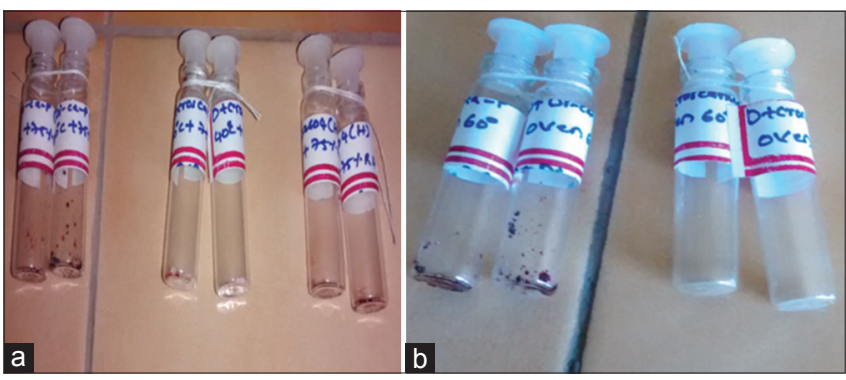

Fig. 6: Photograph of drug and excipient vials (a) stored at $40^{\circ} \mathrm{C}$ and $75 \% \mathrm{RH}(\mathrm{b}) 60^{\circ} \mathrm{C}$

mix has a very small particle size $(<5 \mu \mathrm{m})$ and other is relatively large in such circumstances, the fine powder may coat the surface of the larger particles. The adhesive forces will prevent segregation. This is known as ordered mixing, using this technique, it is possible to produce greater homogeneity than by random mixing [18]. Segregation of various components based on their density difference may be avoided because of this adsorption. The blend uniformity was better achieved by tumbling method than trituration (Table 6a-c). Although the t-test showed no significant difference between the two methods, tumbling has been chosen over the trituration method based on \% CV values. With relevance to the time of blending, between $10 \mathrm{~min}$ and $15 \mathrm{~min}$ tumbling, the mean of the $\% \mathrm{CV}$ values indicates a lesser standard deviation (1.04) at $15 \mathrm{~min}$ of blending. Similar behavior is observed with Q2 and Q3.

\section{Preparation and evaluation of $\mathrm{QHCl}$ tablets}

The powder blends showed adequate flow property and content uniformity, QHCl tablets were prepared by direct compression could successfully be prepared by direct compression technique. The tablets were evaluated and data are given in Table 7. Hardness was found to be $2.5-3 \mathrm{~kg} / \mathrm{cm}^{2}$ for Q1, Q2, but Q3 has a low hardness of $1.5 \mathrm{~kg} / \mathrm{cm}$,
Table 6b: Blend uniformity study for Q2

\begin{tabular}{llllllll}
\hline Amount of QHCl in mg after specific blending time \\
\hline Method & $\begin{array}{l}\text { Sample* } \\
\text { position }\end{array}$ & $\mathbf{1 0}$ min & \multicolumn{3}{l}{$\mathbf{1 5}$ min } \\
& & & & & \\
\hline Tumbling & BL & 12.78 & 11.31 & 11.85 & 11.62 & 11.87 & 11.85 \\
& BR & 12.08 & 11.49 & 11.42 & 11.85 & 11.55 & 12.28 \\
& FL & 11.62 & 12.61 & 12.21 & 12.40 & 11.65 & 11.65 \\
& FR & 11.85 & 11.87 & 11.92 & 11.78 & 12.21 & 11.31 \\
& C & 12.74 & 12.03 & 13.02 & 12.40 & 12.53 & 12.31 \\
& $\%$ CV & 4.29 & 4.42 & 4.9 & 3.04 & 3.39 & 3.24 \\
& Mean & 4.53 & & & 3.22 & & \\
& $\%$ CV & & & & & & \\
Trituration & BL & 10.42 & 9.21 & 9.84 & 8.50 & 7.73 & 7.95 \\
& BR & 9.75 & 8.30 & 10.09 & 9.62 & 8.66 & 8.11 \\
& FL & 9.66 & 10.09 & 9.912 & 8.84 & 8.29 & 8.66 \\
& FR & 10.07 & 10.96 & 8.45 & 8.59 & 8.23 & 8.80 \\
& C & 9.03 & 8.59 & 9.66 & 7.88 & 7.73 & 9.05 \\
& $\%$ CV & 5.28 & 11.61 & 6.83 & 8.59 & 4.19 & 5.47 \\
& Mean & 7.9 & & & 6.08 & & \\
& $\%$ CV & & & & & & \\
\hline
\end{tabular}

*BL: Back left, BR: Back right, FL: Front left, FR: Front right, C: Centre, $\%$ CV: Percentage coefficient of variation, QHCl: Quinapril hydrochloride

Q1, Q2 passed friability test but Q3 failed. Employment of Aerosil may have led to the variation and need to be ascertained. Disintegration time ranged between 1 and 2 min for Q1, Q2, and Q3. The use of water-soluble filler and superdisintegrant crospovidone facilitated the disintegration in spite of the use of $\mathrm{MgO}, \mathrm{MgCO}_{3^{\prime}}$, and Aerosil. As Q3 failed the friability test, it has not been evaluated further. Percentage weight variation was determined which reflects die fill during the compression process. The percentage deviation in weight variation for tablets of weight $<130 \mathrm{mg}$ is $10 \%$ as per USP-29 NF24. The content uniformity test is met with both the formulae with an acceptance value of 17.41 and 18.75 


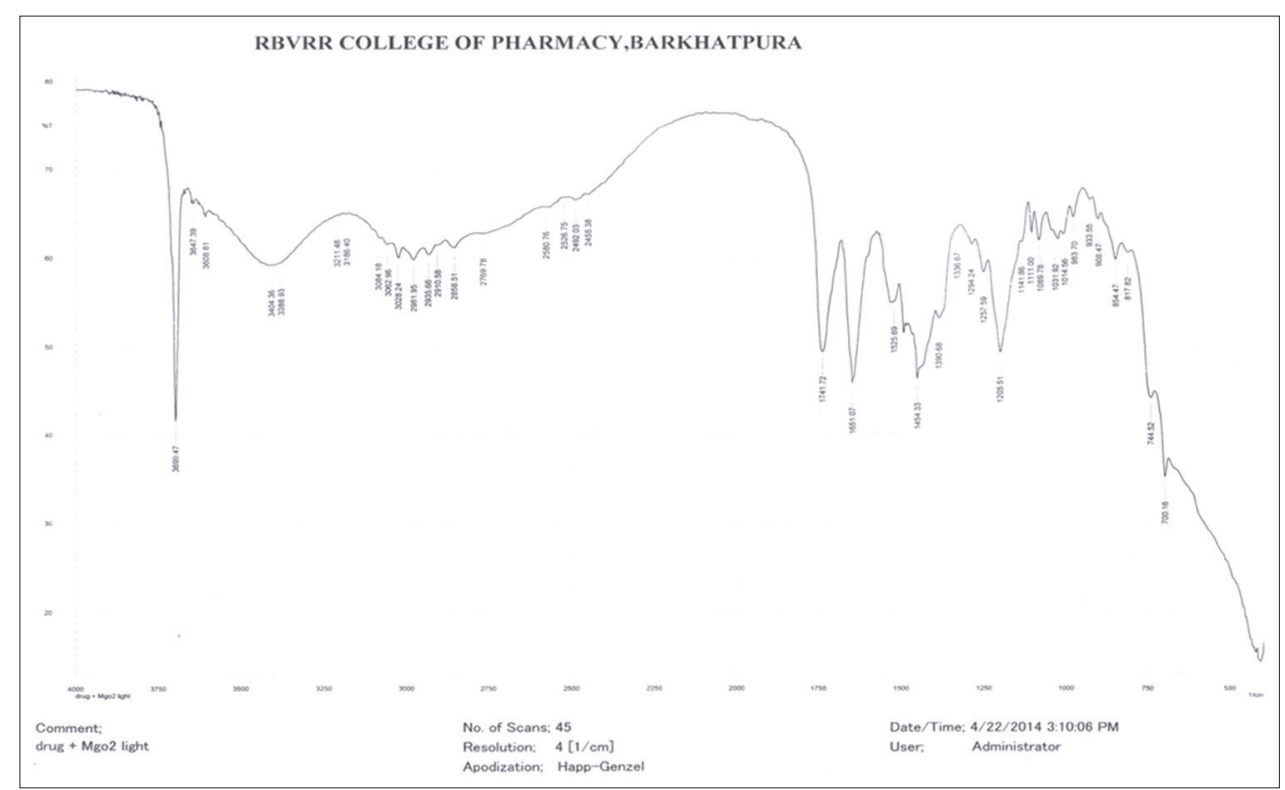

Fig. 7: FTIR spectrum of quinapril hydrochloride + magnesium oxide (light)

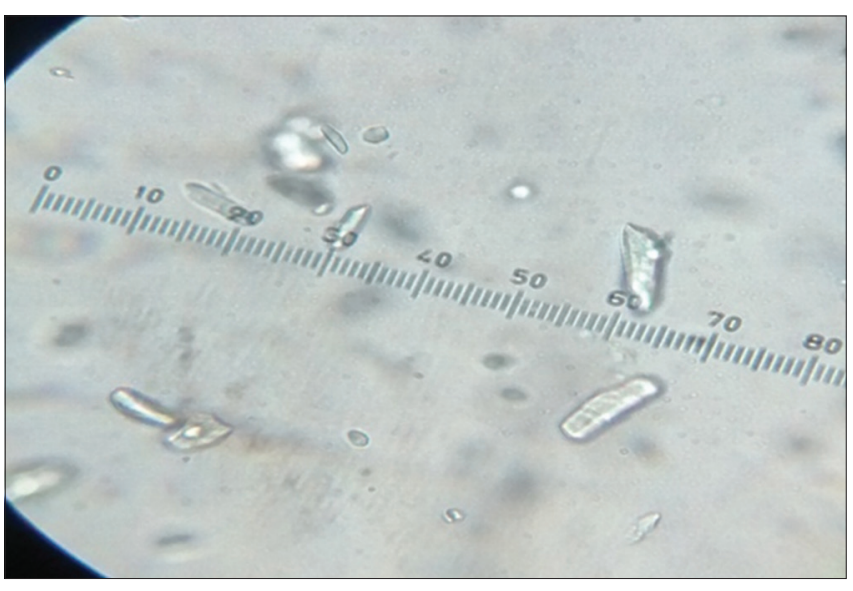

Fig. 8: Optical photomicrograph of quinapril hydrochloride powder at $\times 450$

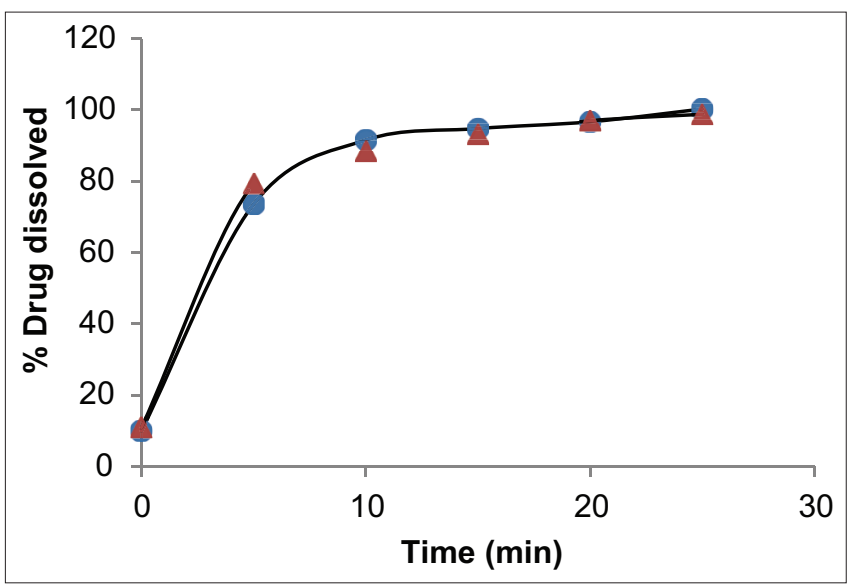

Fig. 9: Percentage drug dissolved versus time plot

Dissolution study of $\mathrm{QHCl}$ tablets

A dissolution study was carried out for Q1 and Q2 (Fig. 9), giving dissolution of $99.2 \%$ and $98.8 \%$, respectively, within $30 \mathrm{~min}$.

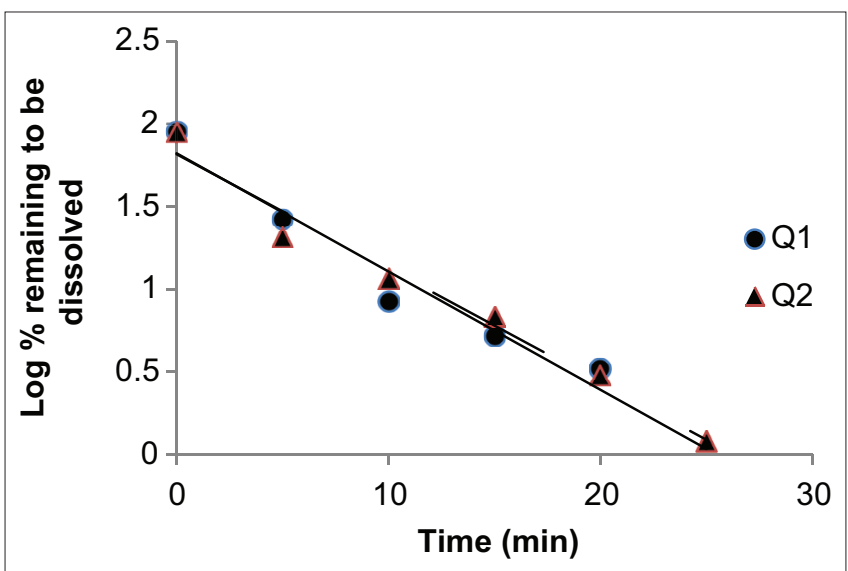

Fig. 10: First-order plot for drug dissolution

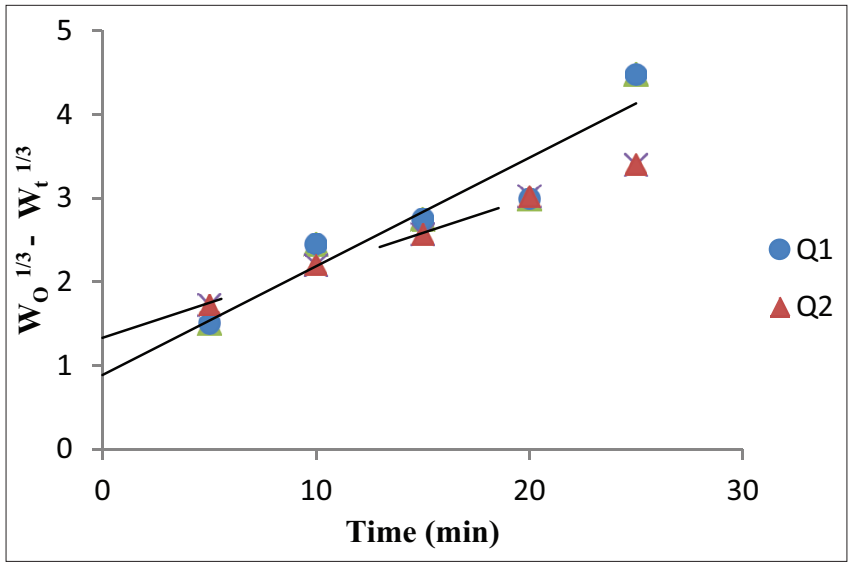

Fig. 11: Hixson-Crowell plot for drug dissolution

Dissolution data is treated by the kinetics of zero-order, first-order, and Hixson-Crowell models (Figs. 10 and 11). From the " $r^{2 "}$ values (Table 8), dissolution is found to follow first-order kinetics and Hixson-Crowell model. 


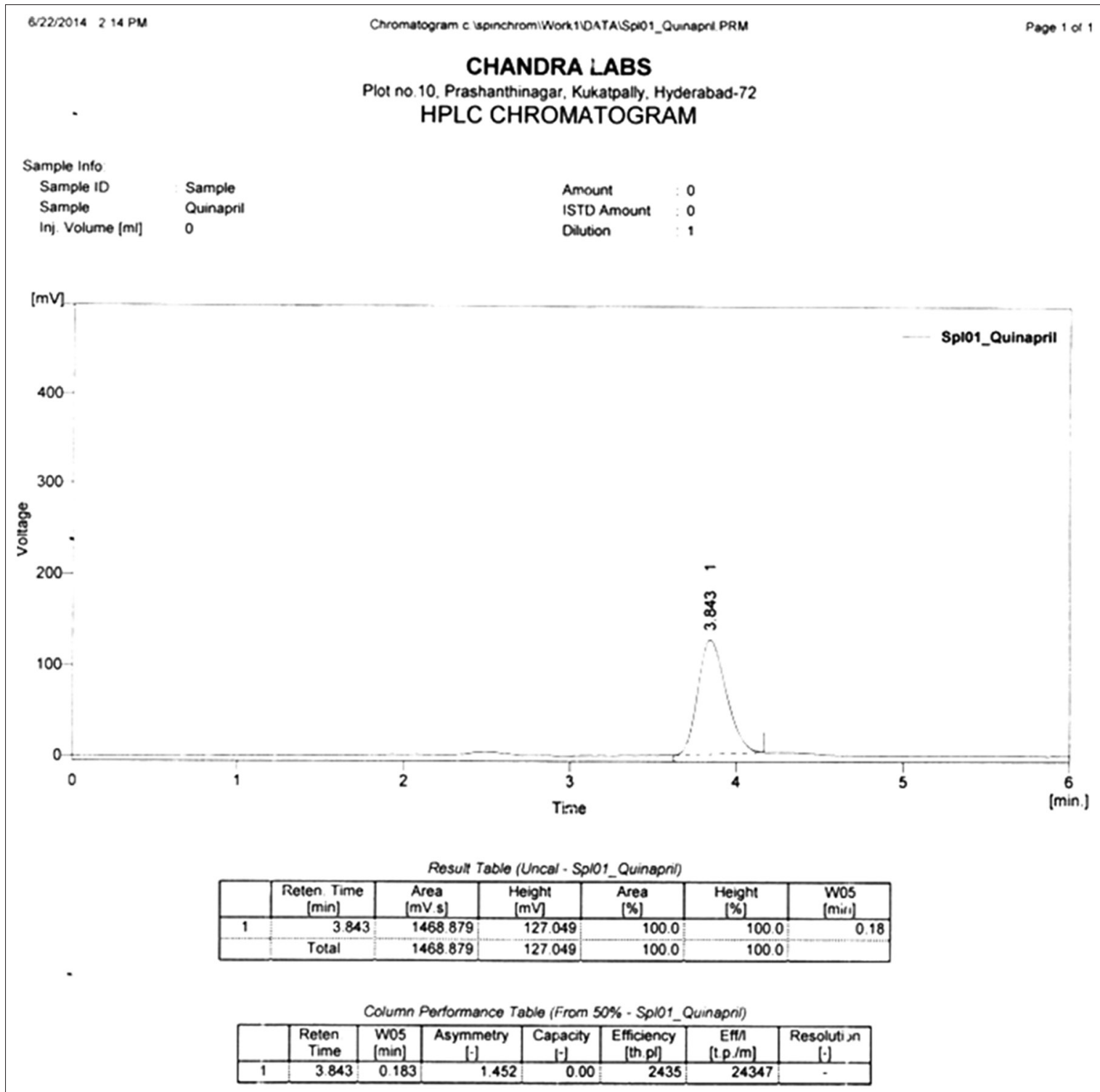

Fig 12: Chromatogram of Q1 after 1 month stability study

Table 6c: Blend uniformity study for Q3

\begin{tabular}{llllllll}
\hline Amount of QHCl in mg after specific blending time \\
\hline Method & \multicolumn{2}{l}{ Sample* } & $\mathbf{1 0}$ min & \multicolumn{5}{l}{$\mathbf{1 5}$ min } \\
& position & & & & & \\
\hline Tumbling & BL & 11.78 & 11.96 & 10.57 & 7.18 & 9.85 & 11.74 \\
& BR & 11.85 & 11.69 & 10.25 & 7.32 & 10.17 & 11.83 \\
& FL & 11.62 & 11.74 & 10.42 & 7.40 & 10.09 & 11.64 \\
& FR & 12.17 & 12.26 & 10.03 & 7.36 & 10.21 & 12.04 \\
& C & 11.81 & 12.01 & 10.19 & 7.27 & 10.05 & 11.85 \\
& $\%$ CV & 1.80 & 1.91 & 2.02 & 1.16 & 1.39 & 1.256 \\
& Mean \%CV & 1.91 & & & 1.26 & & \\
Trituration & BL & 9.8 & 10.42 & 9.05 & 8.07 & 7.81 & 9.19 \\
& BR & 9.32 & 10.07 & 9.32 & 8.05 & 7.27 & 9.32 \\
& FL & 9.19 & 9.84 & 9.18 & 7.88 & 7.41 & 9.50 \\
& FR & 9.46 & 10.09 & 9.11 & 7.68 & 7.36 & 9.48 \\
& C & 9.85 & 9.85 & 8.93 & 7.65 & 7.18 & 9.25 \\
& $\%$ CV & 3.06 & 2.33 & 1.59 & 2.51 & 3.27 & 1.475 \\
& Mean \%CV & 2.32 & & & 2.41 & & \\
\hline
\end{tabular}

*BL: Back left, BR: Back right, FL: Front left, FR: Front right, C: Centre,

$\%$ CV: Percentage coefficient of variation, QHCl: Quinapril hydrochloride
Table 7: Evaluation of quinapril hydrochloride tablets

\begin{tabular}{|c|c|c|c|}
\hline Parameter & Q1 & Q2 & Q3 \\
\hline Hardness $\left(\mathrm{kg} / \mathrm{cm}^{2}\right)$ & 3.3 & 2.5 & 1.5 \\
\hline Friability (\%) & 0.82 & 0.82 & 1 \\
\hline $\begin{array}{l}\text { Disintegration } \\
\text { time (min) }\end{array}$ & 1.33 & 1 & 1.5 \\
\hline Average weight $\pm S D$ & $119.5 \pm 1.023$ & $118.5 \pm 1.03$ & $119 \pm 1.010$ \\
\hline Content uniformity & & & - \\
\hline Acceptance value & 17.41 & 18.75 & - \\
\hline $\begin{array}{l}\text { Percentage mean } \\
\text { assay } \pm S D\end{array}$ & $96.301 \pm 6.581$ & $95.95 \pm 6.75$ & - \\
\hline $\begin{array}{l}\text { Maximum allowed } \\
\text { deviation }\end{array}$ & $81.35-115.64$ & $80.03-116.96$ & - \\
\hline $\begin{array}{l}\text { Percentage cumulative } \\
\text { drug dissolved }\end{array}$ & 99.2 & 98.8 & - \\
\hline
\end{tabular}

SD: Standard deviation

Stability studies

Initialstabilitystudy was conducted for one month at $40^{\circ} \mathrm{C} \pm 2{ }^{\circ} \mathrm{C} / 75 \% \pm 5 \%$ $\mathrm{RH}$ on Q1 and Q2. There was no discoloration observed in the tablets 
Table 8: Dissolution kinetics

\begin{tabular}{|c|c|c|c|c|c|c|c|}
\hline \multirow[t]{2}{*}{ Formula code } & \multicolumn{2}{|c|}{ Zero-order } & \multicolumn{2}{|c|}{ First-order } & \multicolumn{2}{|c|}{ Hixson-Crowell } & \multirow[t]{2}{*}{$t_{50}(\min )$} \\
\hline & $r^{2}$ & $\mathrm{~K}_{0}(\mathrm{mg} / \mathrm{min})$ & $r^{2}$ & $\mathrm{~K}_{1}\left(\mathrm{~min}^{-1}\right)$ & $r^{2}$ & $\mathrm{~K}(\mathrm{mg} / \mathrm{min})$ & \\
\hline Q1 & 0.6584 & 2.99 & 0.970 & -0.164 & 0.91 & 0.13 & 4.22 \\
\hline Q2 & 0.626 & 2.83 & 0.976 & -0.159 & 0.99 & 0.08 & 4.35 \\
\hline
\end{tabular}

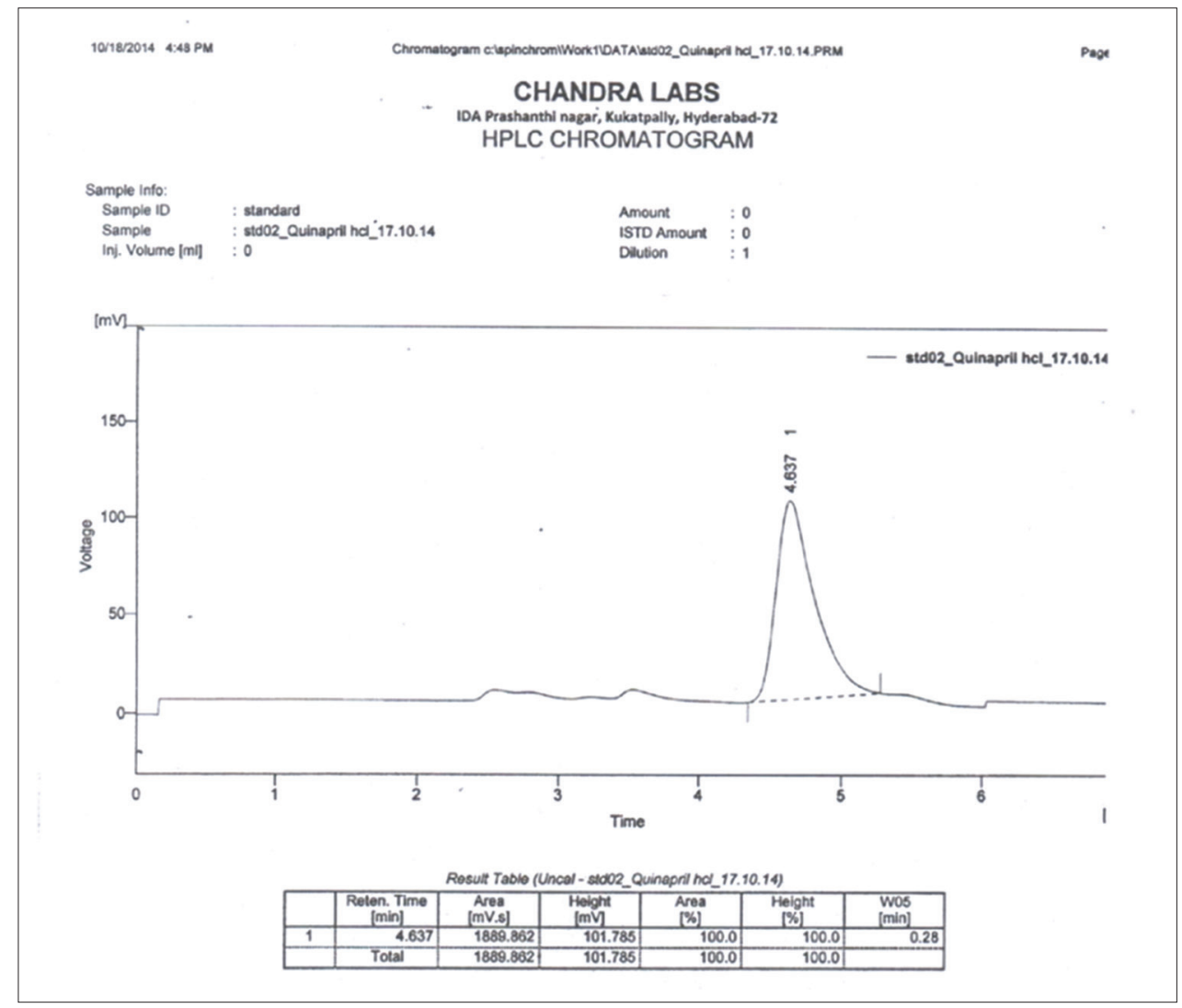

Fig. 13: Chromatogram of Q2 after 1 month stability study

of Q1. The same was evident from chromatogram (Fig. 12) that there are no secondary peaks. The assay was $90 \%$ for Q1. Q2 showed colored spots appeared on tablets after 4 weeks and the chromatogram (Fig. 13) indicated peaks at different retention times indicating some degradation. In $\mathrm{Q} 2$ as $\mathrm{MgCO}_{3}$ is employed, the effectiveness in stabilizing the drug is lesser when compared to $\mathrm{MgO}$ because $\mathrm{MgCO}_{3}$ has only $40 \%$ of $\mathrm{MgO}$ [10]. Tablet hardness and disintegration did not show variation after 1 month.

\section{CONCLUSION}

QHCl which is a low dose antihypertensive agent has stability and excipients compatibility issues. As evident from the stability information, the tablets need to be stored in cool dry conditions. A direct compression technique has been employed to prepare tablets. The formulation for direct compression could be prepared by employing stabilizers for the drug. Tumbling and trituration methods have been employed for blending. Blend uniformity, thereby content uniformity for the low dose drug could be attained. $\mathrm{QHCl}$ tablets could successfully be prepared by the direct compression method.

\section{ACKNOWLEDGMENT}

The authors are thankful to Aurobindo Pharma Limited, Hyderabad, for the gift sample of quinapril hydrochloride. They express their gratitude to the Principal and Management of RBVRR Women's College of Pharmacy, Barkatpura, Hyderabad, for all the facilities and support to carry out this work. The authors are also grateful to Acharya and BM Reddy College of Pharmacy, Bengaluru, for the support towards the preparation of the manuscript.

\section{AUTHORS' CONTRIBUTIONS}

The authors declare that the work reported herein was performed by the two authors. Dr Madhavi designed the study, procured the necessary chemicals required, supervised the entire work, and proofread the manuscript before submission. On the other hand, Ms Shweta performed the laboratory experiments and drafted the manuscript.

\section{CONFLICTS OF INTEREST}

The authors declare that they have no conflicts of interest regarding the publication of this article.

\section{REFERENCES}

1. Liberman HA, Lachman L, Schwartz JB. Pharmaceutical Dosage Forms: Tablets. $2^{\text {nd }}$ ed., Vol. 1. USA: Marcel Dekker; 1989.

2. Accupril (Quinapril Hydrochloride) Product Monograph. Canada: Parke Davis and Company Pfizer Inc.; 2017. Available from: https://www.pfizer.ca/sites/default/files/201710/accupril pm_200979_e 14mar2017 clean.pdf. [Last accessed on 2019 Nov 21].

3. Stanisz B, Paszun S, Strzyzycka N, Ptaszyński E. Influence of humidity and hydroxypropyl cellulose, hydroxypropylmethyl cellulose, glyceryl behenate or magnesium stearate on the degradation kinetics of quinapril hydrochloride in solid phase. Acta Pol Pharm 2010;67:99-102. 
4. Stanisz B. The influence of pharmaceutical excipients on quinapril hydrochloride stability. Acta Pol Pharm 2005;62:189-93.

5. Stanisz B. The stability of quinapril hydrochloride--a mixture of amorphous and crystalline forms (QHCl-AC)--in solid phase. Acta Pol Pharm 2003;60:443-9.

6. Guo Y, Byrn SR, Zografi G. Effects of lyophilization on the physical characteristics and chemical stability of amorphous quinapril hydrochloride. Pharm Res 2000;17:930-5.

7. Palem CR, Gannu R, Yamsani SK, Yamsani VV, Yamsani MR. Development of bioadhesive buccal tablets for felodipine and pioglitazone in combined dosage form: In vitro, ex vivo, and in vivo characterization. Drug Deliv 2011;18:344-52.

8. Abed KK, Hussein AA, Ghareeb MM, Abdulrasool AA. Formulation and optimization of orodispersible tablets of diazepam. AAPS PharmSciTech 2010;11:356-61.

9. Fung HL, Yap SK, Rhodes CT. Development of a stable sublingual nitroglycerin tablet II: Formulation and evaluation of tablets containing povidone. J Pharm Sci 1976;65:558-60.

10. Daniel JE, Harris MR, Hokanson GC, Weiss J. Stabilization of Quinapril Using Magnesium Oxide. United States Patent, Patent No. US 6417196B1; 2002. Available from: https://www.patents.google. com/patent/US6417196. [Last accessed on 2019 Apr 18]

11. Harris M, Hokanson G, Murthy K, Reisch R, Frank W. Stabilized pharmaceutical Compositions Containing ACE Inhibitors. European Patent, Patent No. EP0280999; 1993. Available from: https://www.
patents.google.com/patent/EP0280999A2/en. [Last accessed on 2019 Apr 18].

12. Murthy KS, Harris MR, Hokanson GC, Reisch RG Jr., Waldman F, Fawzi MB. Stabilized Drug Compositions. United States Patent, Patent No. US4793998A; 1988. Available from: https://www.patents.google. com/patent/US4793998. [Last accessed on 2019 Apr 18].

13. Mali AD, Bathe RS. Development and evaluation of gastroretentive floating tablets of quinapril HCL by direct compression technique. Int $\mathrm{J}$ Pharm Pharm Sci 2017;9:35-46.

14. Ranade AN, Ranpise NS, Sanap GS, Kulkarni RR. Development and in vitro evaluation of buccal tablet of quinapril hydrochloride. Indian $\mathrm{J}$ Pharm Educ Res 2011;45:364-9.

15. Qui Y, Chen Y, Zhang GZ. Developing Solid Oral Dosage Forms Pharmaceutical Theory and Practice. $1^{\text {st }}$ ed. New York: Elsiever Inc.; 2009. p. 125.

16. Bramhe NN, Kilor VA. Evaluation and optimization of Lepidium sativum seed mucilage as binder in tablet formulation. Int $\mathrm{J}$ Pharm Pharm Sci 2014;6:285-91.

17. Uniformity of Dosage Units, the United States Pharmacopeia: USP 29: The National Formulary NF, United States Pharmacopeial Convention; 2006. Available from: http://www.ftp.uspbpep.com/v29240/ usp29nf24s0_c905h.html.

18. Deveswaram R, Bharath S, Concepts and techniques of pharmaceutical powder mixing process: A current update. Res J Pharm Technol $2009 ; 2: 245-9$ 